Boise State University

ScholarWorks

$10-15-2008$

\title{
Ambient Temperature Influences Diet Selection and Physiology of an Herbivorous Mammal, Neotoma albigula
}

M.D. Dearing

University of Utah

Jennifer S. Forbey

Boise State University

J.D. McLister

Indiana University South Bend

L. Santos

University of Washington 


\section{Ambient Temperature Influences Diet Selection and Physiology of an Herbivorous Mammal, Neotoma albigula}

\author{
M. D. Dearing ${ }^{1, \star}$ \\ J. S. Forbey ${ }^{2, \dagger}$ \\ J. D. McLister ${ }^{3}$ \\ L. Santos ${ }^{4}$ \\ ${ }^{1}$ Department of Biology, University of Utah, Salt Lake City, \\ Utah 84112; ${ }^{2}$ Department of Pharmaceutics and \\ Pharmaceutical Chemistry, University of Utah, Salt Lake \\ City, Utah 84112; ${ }^{3}$ Department of Biological Sciences, \\ Indiana University South Bend, South Bend, Indiana 46634; \\ ${ }^{4}$ College of Forest Resources, University of Washington, \\ Seattle, Washington 98195
}

Accepted 3/20/2008; Electronically Published 10/16/2008

\section{ABSTRACT}

The whitethroat woodrat (Neotoma albigula) eats juniper ( $\mathrm{Ju}$ niperus monosperma), but the amount of juniper in its diet varies seasonally. We tested whether changes in juniper consumption are due to changes in ambient temperature and what the physiological consequences of consuming plant secondary compounds (PSCs) at different ambient temperatures might be. Woodrats were acclimated to either $20^{\circ} \mathrm{C}$ or $28^{\circ} \mathrm{C}$. Later, they were given two diets to choose from (50\% juniper and a nontoxic control) for $7 \mathrm{~d}$. Food intake, resting metabolic rate (RMR), and body temperature $\left(T_{\mathrm{b}}\right)$ were measured over the last $2 \mathrm{~d}$. Woodrats at $28^{\circ} \mathrm{C}$ ate significantly less juniper, both proportionally and absolutely, than woodrats at $20^{\circ} \mathrm{C}$. RMRs were higher for woodrats consuming juniper regardless of ambient temperature, and $T_{\mathrm{b}}$ was higher for woodrats consuming juniper at $28^{\circ} \mathrm{C}$ than for woodrats eating control diet at $28^{\circ} \mathrm{C}$. Thus, juniper consumption by $N$. albigula is influenced by ambient temperature. We conclude that juniper may influence thermoregulation in N. albigula in ways that are helpful at low temperatures but harmful at warmer temperatures in that juniper PSCs may be more toxic at warmer temperatures. The results suggest that increases in ambient temperature associated with climate change could significantly influence foraging behavior of mammalian herbivores.

\footnotetext{
*Corresponding author; e-mail: denise.dearing@utah.edu.

${ }^{\dagger}$ Present address: Department of Biological Sciences, Boise State University, Boise, Idaho 83725 .

Physiological and Biochemical Zoology 81(6):891-897. 2008. (C) 2008 by The University of Chicago. All rights reserved. 1522-2152/2008/8106-7213\$15.00 DOI: $10.1086 / 588490$
}

\section{Introduction}

The most recent report from the Intergovernmental Panel on Climate Change predicts that the average temperature of the global surface will increase by up to $6.4^{\circ} \mathrm{C}$ by the end of this century under the current unregulated rate of $\mathrm{CO}_{2}$ emissions (Solomon et al. 2007). The report predicts that the overall effect of warming across most parts of the world will result in a decrease in the number of very cold days and nights in the winter and an increase in the number of hot days and warm nights during summer, and warming is predicted to be even greater in arid regions of the world.

Increases in temperature of this magnitude have marked consequences on insect herbivores (see Bale et al. 2002 for a recent review). In general, insect herbivory on a global scale is directly constrained by temperature. Although not all insect species respond similarly, the widespread effect of increasing global temperature is predicted to accelerate development and enhance overwinter survival of insects (Lindroth et al. 1997). Thus, the vast majority of insect herbivores should respond favorably to increasing temperatures, resulting in an elevated intensity of insect herbivory and a greater diversity of insect herbivores (Bale et al. 2002).

The effect of increased temperature on mammalian herbivory has not been examined. However, it is unlikely that mammalian herbivores would be affected in the same way as insect herbivores because, as homeotherms, mammals would experience fundamentally different physiological consequences of ambient-temperature changes. For nonhomeothermic insects, metabolic rate and daily caloric intake generally increase with ambient temperature, whereas mammalian metabolic rates follow a temperature response curve whereby metabolic rate is minimal over a specific range of ambient temperatures (i.e., the thermoneutral zone, or TNZ) but starts to increase when energy is allocated toward thermoregulation as ambient temperature either decreases or increases beyond the lower and upper critical temperatures of the TNZ (Schmidt-Nielsen 1993).

Two independent lines of evidence suggest that mammalian herbivores that consume diets with plant secondary compounds (PSCs) will be affected by increases in ambient temperatures. First, there are physiological connections between the ingestion of PSCs and the thermoregulatory physiology of mammals (Bozinovic and Novoa 1997; McLister et al. 2004). Because thermoregulatory physiology is coupled to changes in ambient temperature, it is reasonable to assume that climate change 
could influence plant-mammal interactions through the effects of PSCs on thermoregulation. Furthermore, pharmacological studies on laboratory rodents indicate that the toxicity of many xenobiotics is temperature dependent. In several cases, increases in ambient temperature decrease the dose required for toxicity (Gordon et al. 1988; Gordon 1993).

We selected Neotoma albigula, the whitethroat woodrat, to begin to evaluate the interactions of temperature and PSCs in mammalian herbivores. Neotoma albigula is a generalist herbivore common in the Great Basin and Sonoran deserts of the southwestern United States (Macedo and Mares 1988). In areas of the Great Basin Desert, juniper (Juniperus monosperma and Juniperus osteosperma) composes $18 \%-35 \%$ of its diet (Dial 1988; M. D. Dearing, personal observations). Juniper has notable levels of PSCs, particularly terpenes and, to a lesser extent, phenolics (Adams et al. 1981; Núñez-Hernández et al. 1989). The limited amount of juniper that $N$. albigula can consume is largely dictated by PSCs and not nutrient content (Dearing et al. 2000; Sorensen et al. 2005b). The diet composition of $N$. albigula is seasonally variable, with a high percentage of juniper during the winter but a low percentage during the summer (Dial 1988). One hypothesis to explain the seasonal shift in diet of N. albigula is that a reduced availability of herbaceous, ephemeral plants forces woodrats to rely more heavily on juniper during the winter. Alternatively, N. albigula may regulate juniper consumption in conjunction with physiological interactions among PSCs, ambient temperature, and thermoregulation. Our previous work on the effects of juniper on thermoregulation in woodrats revealed significant effects of temperature acclimation and diet such that N. albigula acclimated to warmer temperatures $\left(25^{\circ} \mathrm{C}\right)$ had higher costs of thermoregulation when feeding on a diet containing juniper than woodrats acclimated to lower temperatures $\left(18^{\circ} \mathrm{C}\right.$; McLister et al. 2004). Furthermore, the results suggested that the foraging behavior and physiology of the generalist woodrat, N. albigula, may change with increasing ambient temperatures such that plants with secondary compounds would be less preferred under warmer conditions.

In this study, we tested the hypothesis that seasonal changes in diet selection in N. albigula are dependent on ambient temperature and not the relative availability of juniper by offering individual woodrats a choice of juniper and nonjuniper diets and comparing the proportional voluntary consumption of juniper at different temperatures. We also investigated the effect of temperature-altered diet selection on thermoregulation by measuring the resting metabolic rate (RMR) and the body temperature $\left(T_{\mathrm{b}}\right)$ of animals acclimated to different temperatures.

\section{Material and Methods}

\section{Animals}

A total of nine adult Neotoma albigula were used. All animals were either trapped in Coconino County, Arizona, or were born in captivity to pregnant mothers that were collected from the same location. We also collected fresh juniper from the animal collection sites and stored it on dry ice until transfer to a freezer $\left(-20^{\circ} \mathrm{C}\right)$.

From the time of their capture or birth, to the beginning of the experiment, all animals were maintained at $22^{\circ} \mathrm{C}$ on a $12 \mathrm{~L}: 12 \mathrm{D}$ light cycle in the animal facility of the Biology Department, University of Utah. Each animal was maintained in the animal facility on a diet of rabbit chow (Harland Teklad 2031) for at least 6 mo before the start of the experiment. All experiments were approved by the University of Utah Institutional Animal Care and Use Committee (protocol 04 0212).

\section{Temperature and Diet Treatments}

The basis of the experiment was to compare voluntary intake of juniper by woodrats after acclimation to two ambient temperatures. Woodrats were housed in metabolic cages (Nalgene $650-0100)$ and acclimated to either $20^{\circ} \mathrm{C}(n=4)$ or $28^{\circ} \mathrm{C}$ $(n=5)$ in a standard animal room with central air/heating for temperature control. These temperatures were selected to be either just below the TNZ $\left(20^{\circ} \mathrm{C}\right)$ or within the $\mathrm{TNZ}\left(28^{\circ} \mathrm{C}\right.$; McLister et al. 2004) and are reflective of temperatures in the animals' natural habitat. At the study site from which the woodrats were collected, temperatures are highest during the summer months and are similar to the warmer acclimation temperature used in this study $\left(28^{\circ} \mathrm{C}\right.$; http://www.wrcc.dri.edu/cgi-bin/ cliMAIN.pl?az9542). The mean maximum temperatures for May-September at the study site exceeded the warmer acclimation temperature used in this study $\left(28^{\circ} \mathrm{C}\right)$. Moreover, 3 mo (June-August) have average daily temperatures close to $28^{\circ} \mathrm{C}$. Woodrats were acclimation for $21 \mathrm{~d}$ before initiation of dietary treatment, during which they were fed rabbit chow. Woodrats did not differ in body mass between the two acclimation temperatures at the completion of the $21-\mathrm{d}$ acclimation period $\left(20^{\circ} \mathrm{C}: 200 \pm 3.8 \mathrm{~g} ; 28^{\circ} \mathrm{C}: 194 \pm 6.3 \mathrm{~g} ; F_{1,8}=0.59, P>0.05\right)$.

Three diet treatments were used during the experiment. The first two diets and their order of feeding were intended to preexpose woodrats to the diets offered during the choice trial. The "nontoxic" diet was a control formulation that emulated the nutritional contents of juniper foliage while lacking PSCs (see Sorensen et al. $2005 b$ for nutritional composition). This diet consisted of ground rabbit chow (Harland Teklad 2031), supplemented with cellulose, starch, sucrose, protein, oil vitamins, and minerals. We used the nontoxic diet as a control to compare to the choice trial. The second diet treatment, $25 \%$ juniper (dry weight $[\mathrm{dw}]$ ) and $75 \%$ control diet (dw), was provided to gradually acclimate woodrats to the $50 \%$ juniper diet to be used in the choice trial. Previous feeding trials revealed that woodrats ingest greater quantities of juniper with gradual concentration increases of juniper in the diet. The third diet was 50\% juniper (dw) and 50\% control diet (dw). Junipercontaining diets were prepared from juniper collected at the animal collection site and frozen until use. Before the start of the experiment, juniper foliage cleaned of stems and twigs was ground on dry ice and homogenized in a single batch and stored in the freezer until diet preparation. All control and juniper 
diets were prepared daily during the experiment and contained approximately $50 \%$ water by wet weight. We could not eliminate evaporation of terpenes ( $\sim 0 \%$ loss after $12 \mathrm{~h}$; A.-M. M. Torregrossa, personal communication) during diet presentation; therefore, we focused on keeping terpene concentration as high as possible by making diets daily from frozen juniper stock, adding water to the diet, and presenting freshly made diet to woodrats just before their primary feeding time (dark onset).

The three diet treatments were used in the following sequence: (1) nontoxic only, (2) 25\% juniper only, and (3) a choice of nontoxic and 50\% juniper diets. The third treatment in the sequence was the choice trial used to compare diet selection under the two temperature regimes. The nontoxic diet was used for the first $3 \mathrm{~d}$, followed by the $25 \%$ juniper diet for $2 \mathrm{~d}$, followed by the choice trial for $7 \mathrm{~d}$. The diets were offered to the woodrats through feeding hoods attached to the metabolic cages. The hoods prevent significant movement of diet within the cage and have separate collectors for spillage. All diets were fed ad lib. During the choice trial, woodrats were presented with equal amounts (30 g each) of nontoxic and 50\% juniper presented simultaneously in separate feeder hoods. The amount of diet given in each feeder exceeded daily intake. We measured food intake as the average of the last $2 \mathrm{~d}$ of each diet treatment.

\section{Metabolic Rate and Body Temperature Measurements}

On the last $2 \mathrm{~d}$ of the nontoxic diet and the choice trial, RMR and $T_{\mathrm{b}}$ were measured. Each animal was placed inside a 500$\mathrm{mL}$ metabolic chamber for $1 \mathrm{~h}$. A temperature probe inside each chamber provided an accurate measurement of ambient temperature. Chambers were covered in black paper to minimize disturbance of animals. The RMR of woodrats were collected between 0900 and 1400 hours. Because woodrats are nocturnal and the majority of food consumption occurs at the beginning of the dark cycle, the diurnal measurement period constituted the time when specific dynamic action is minimal and woodrats are in the resting phase of their activity cycle (M. D. Dearing, personal observation). A constant airflow of 500 $\mathrm{mL} / \mathrm{min}$ was drawn through the chamber. Each woodrat was acclimated to the metabolic chamber for the first half-hour. During the second half-hour, the effluent airflow was channeled through an AEI oxygen analyzer after first passing through drying tubes containing Drierite and barium hydroxide to remove water vapor and $\mathrm{CO}_{2}$, respectively. The oxygen analyzer calculated the fractional volume of oxygen in the effluent air to a precision of $0.01 \%$. LabVIEW software was used to calculate the total volume of oxygen consumed, adjusted to STPD, every $30 \mathrm{~s}$, following the procedure outlined by Depocas and Hart (1957) for an open-circuit system with the outlet air metered. From each half-hour of oxygen consumption data recorded for each animal, the RMR was taken to be the average rate of oxygen consumption during the 6-min interval in which oxygen consumption was lowest. RMR was measured twice for each animal on each treatment on two consecutive days, and these values were averaged within a treatment.

Immediately after each hour inside the metabolic chamber, $T_{\mathrm{b}}$ was measured by inserting a probe $2-3 \mathrm{~cm}$ into the rectum. The temperature probe was a thermistor calibrated at $36^{\circ} \mathrm{C}$ and $40^{\circ} \mathrm{C}$ to generate a linear equation for converting the resistance of the thermistor into degrees Celsius. The thermistor resolved differences of $0.05^{\circ} \mathrm{C}$. To minimize direct handling of the animals during $T_{\mathrm{b}}$ measurement, animals were transferred directly and voluntarily from the metabolic chamber to a short plastic tube that exposed the hindquarters of the animal. The temperature probe was inserted for $45 \mathrm{~s}$, and the woodrats were held secure in position in the tube by lightly holding the base of the tail between the thumb and forefinger.

Repeated-measures ANOVAs were used to separately evaluate the response variables of body mass, intake, RMR, and $T_{\mathrm{b}}$, with temperature treatment $\left(20^{\circ} \mathrm{C}\right.$ vs. $\left.28^{\circ} \mathrm{C}\right)$ as the between-subjects effect and dietary treatments (nontoxic vs. choice) as the within-subjects effect. The $25 \%$ juniper diet treatment was an acclimation treatment; thus, we did not include this treatment in the statistical analyses. Separate one-way ANOVAs were used to examine the effect of temperature on the absolute and relative intakes of the nontoxic and 50\% juniper diets during the choice trial. Ad hoc comparisons were performed within each temperature treatment with a Bonferroni-corrected $\alpha(0.025$ for two comparisons) when significant interactions between temperature and diet treatment were detected. All statistical analyses were performed using JMP 4 software for Macintosh.

\section{Results}

Woodrats did not differ in body mass in response to temperature or diet treatments (Table 1). Woodrats were in steady state for body mass throughout the experiment.

Temperature significantly affected total food intake. Woodrats acclimated to $20^{\circ} \mathrm{C}$ had intakes $1.9-2.2$ times those of woodrats acclimated to $28^{\circ} \mathrm{C}$ treatment (Table 1 ). Diet treatment did not affect total food intake (Table 1). However, ambient temperature altered diet selection, as revealed by differential diet composition across temperature treatments. During the choice trial, when animals could freely select the amount of juniper in the diet, woodrats at $28^{\circ} \mathrm{C}$ voluntarily consumed relatively and absolutely less juniper than woodrats at $20^{\circ} \mathrm{C}$. Animals acclimated to $20^{\circ} \mathrm{C}$ had juniper intakes about four times those at $28^{\circ} \mathrm{C}$ (\% juniper intake: $17.4 \pm 4.0$ at $20^{\circ} \mathrm{C}$ vs. $4.2 \pm 1.0$ at $\left.28^{\circ} \mathrm{C} ; F_{1,8}=12.9, P=0.009\right)$. Temperature did not significantly affect the absolute amount of nontoxic diet consumed during the choice treatment (nontoxic diet intake per day: $9.6 \pm 0.2 \mathrm{~g}$ at $20^{\circ} \mathrm{C}$ vs. $7.1 \pm 0.5 \mathrm{~g}$ at $28^{\circ} \mathrm{C} ; F_{1,8}=1.56$, $P>0.05$ ).

RMR was affected by both temperature and diet selection (Table 1). Woodrats at $20^{\circ} \mathrm{C}$ had RMRs $1.5-1.6$ times those of woodrats at $28^{\circ} \mathrm{C}$ regardless of diet treatment (Table 1). Diet treatment also had a significant effect on RMR. RMR was significantly elevated when juniper was ingested in the choice 
Table 1: Summary of ANOVAs for body mass, total intake, resting metabolic rate (RMR), and body temperature $\left(T_{\mathrm{b}}\right)$ in woodrats

\begin{tabular}{|c|c|c|c|c|c|c|c|c|}
\hline & \multirow{2}{*}{\multicolumn{2}{|c|}{ Diet Treatment }} & \multicolumn{6}{|c|}{ ANOVA Results ${ }^{\mathrm{a}}$} \\
\hline & & & \multicolumn{2}{|c|}{ Temperature } & \multicolumn{2}{|l|}{ Diet } & \multicolumn{2}{|c|}{$\mathrm{T} \times \mathrm{D}$} \\
\hline & Nontoxic & Choice & $F$ & $P$ & $F$ & $P$ & $F$ & $P$ \\
\hline Body mass (g) & & & 2.24 & .18 & 4.64 & .07 & .02 & .90 \\
\hline $28^{\circ} \mathrm{C}$ & $184 \pm 6.29$ & $189 \pm 9.01$ & & & & & & \\
\hline $20^{\circ} \mathrm{C}$ & $200 \pm 3.67$ & $205 \pm 7.05$ & & & & & & \\
\hline Total intake (g DM/d) & & & 34.6 & .0006 & 1.85 & .22 & .45 & .52 \\
\hline $28^{\circ} \mathrm{C}$ & $6.3 \pm .75$ & $7.8 \pm .61$ & & & & & & \\
\hline $20^{\circ} \mathrm{C}$ & $13.9 \pm 1.05$ & $14.4 \pm 1.58$ & & & & & & \\
\hline RMR (mL/min) & & & 39.4 & .0004 & 12.4 & .01 & .13 & .73 \\
\hline $28^{\circ} \mathrm{C}$ & $1.5 \pm .15$ & $2.1 \pm .14$ & & & & & & \\
\hline $20^{\circ} \mathrm{C}$ & $2.5 \pm .28$ & $3.2 \pm .15$ & & & & & & \\
\hline$T_{\mathrm{b}}\left({ }^{\circ} \mathrm{C}\right)$ & & & .88 & .38 & 22.9 & .002 & 5.53 & .05 \\
\hline $28^{\circ} \mathrm{C}$ & $37.4 \pm .21$ & $39.0 \pm .26$ & & & & & & \\
\hline $20^{\circ} \mathrm{C}$ & $37.4 \pm .59$ & $38.0 \pm .62$ & & & & & & \\
\hline
\end{tabular}

Note. Results are presented as mean $\pm \mathrm{SE}$. DM $=$ dry mass. Woodrats were acclimated to $28^{\circ} \mathrm{C}$ or $20^{\circ} \mathrm{C}$ and fed a nontoxic control diet followed by a choice between the control diet and a diet containing $50 \%$ juniper in separate feeders. Temperature is the between-subjects effect, diet is the within-subjects effect, and " $\mathrm{T} \times \mathrm{D}$ " represents their interaction.

${ }^{a}$ For all ANOVA results, $\mathrm{df}=1,7$.

treatment, compared to RMR on the nontoxic treatment. At $28^{\circ} \mathrm{C}$, the RMR of woodrats on the choice treatment was 1.4 times that of woodrats on the nontoxic treatment, whereas at $20^{\circ} \mathrm{C}$, the RMR of woodrats on the choice treatment was 1.3 times that of woodrats on the nontoxic treatment (Table 1). The temperature $\times$ treatment interaction was not significant.

The $T_{\mathrm{b}}$ was not affected by ambient temperature but was affected by diet selection (Table 1). The effect of diet selection on $T_{\mathrm{b}}$ was not uniform across temperature treatments, as indicated by a significant interaction effect (Table 1 ). Woodrats acclimated to $28^{\circ} \mathrm{C}$ had $T_{\mathrm{b}} 1.6^{\circ} \mathrm{C}$ higher on the choice treatment than on the nontoxic treatment, whereas woodrats acclimated to $20^{\circ} \mathrm{C}$ had $T_{\mathrm{b}} 0.6^{\circ} \mathrm{C}$ higher on the choice treatment than on the nontoxic treatment, although this latter difference was not significant.

\section{Discussion}

Ample evidence indicates that global warming directly affects insect herbivory (Bale et al. 2002). However, far fewer data exist for the effect of global warming on mammalian herbivory. Our results suggest that ambient temperature can influence diet selection in mammalian herbivores and that increasing temperatures associated with climate change may restrict the ability of mammalian herbivores to feed on plants high in PSCs. Previous studies revealed that ambient temperature influences diet selection of mammals with respect to nutrient content. For example, changes in ambient temperature can cause a change in the proportion of lipids ingested or a switch in preference from unsaturated to saturated fats (Aubert et al. 1995; Hiebert et al. 2000). The diets we used, however, were nutritionally equivalent and differed only in the presence or absence of ju- niper PSCs, known for their strong influence on ingestive behavior. To our knowledge, the work presented here is the first to examine the interaction of PSCs and temperature on diet selection in herbivorous mammals, and the results show a profound effect of ambient temperature on diet selection. At warmer temperatures, woodrat herbivores significantly reduced the quantity of PSCs in their diet. Moreover, the incorporation of even small amounts of PSCs in the diet had a larger effect on $T_{\mathrm{b}}$ and metabolic rate at warmer temperatures than at cooler temperatures. We propose that woodrats reduce or avoid consumption of juniper in warmer temperatures (summer), when PSC ingestion causes a marked physiological challenge, but consume juniper during colder periods (winter), when they either have higher tolerance to toxins or derive an energetic benefit from juniper.

We acknowledge the limitations of this research in that we investigated a single species of herbivore and a single plant species. However, the potential implications of temperature effects on diet and foraging choices warrant further research to determine the generality of these results among mammalian herbivores. For the remainder of the discussion, we consider first the effects of climate change on woodrats and then the possible physiological mechanisms responsible for the observed differences in juniper consumption between woodrats at different temperatures. We expand on our results to speculate about mammalian herbivores in general.

\section{Woodrats and Climate Change}

Our results suggest that temperature changes associated with climate change could significantly affect the foraging ecology 
of woodrat herbivores. A series of elegant articles by Smith and colleagues demonstrated that Neotoma albigula, as well as other species of Neotoma, are sensitive to changes in temperature on both evolutionary and ecological timescales (Smith et al. 1995, 1998; Smith and Betancourt 2006). They found that body size of Neotoma responded to changes in temperature in a manner that conforms to Bergmann's rule: as temperature increased, body size decreased. For example, in Neotoma cinerea, temperature fluctuations over the past 25,000 yr accounted for a significant fraction of the variation observed in body size. As temperatures increased, body size decreased by as much as $30 \%$ (Smith et al. 1995). Changes in body size of Neotoma have also been witnessed in ecological time. In an 8 -yr period, body mass of $N$. albigula decreased by $\sim 9 \%$ during a $3{ }^{\circ} \mathrm{C}$ rise in average maximal temperature (Smith et al. 1998).

The work of Smith and colleagues indicates that the increases in global temperatures predicted for the next century will likely result in a decrease in the body size of woodrats (Smith et al. 1995, 1998; Smith and Betancourt 2006). Whether a reduction in body size will exacerbate or offset temperature-induced toxicity of PSCs is depends on how the TNZ changes with alterations in body size. The effect of increasing global temperatures on temperature-induced toxicities could be magnified if the lower critical temperature of the TNZ of smaller woodrats is higher than that of larger woodrats. In this case, a reduction in body size concomitant with an increase in lower critical temperature may result in temperature-induced toxicities being realized at higher ambient temperatures. Alternatively, if smaller woodrats have narrower TNZs than larger woodrats (Vaughn et al. 2000), then the effect of temperature-induced toxicity may be offset. The connections among body size, TNZ, and temperature-dependent toxicity requires further study to determine the exact nature of the relationship.

\section{Implications for Other Mammalian Herbivores}

Recent work on the North American pika (Ochotona princeps), a small herbivorous lagomorph, suggests that some mammalian herbivores may already be experiencing the effects of global warming (Beever et al. 2003; Grayson 2005). A resurvey of 25 populations of the North American pika across the Great Basin indicated that $28 \%$ of the original populations surveyed within the past $100 \mathrm{yr}$ were locally extinct (Beever et al. 2003). Elevated temperature was suggested as a partial but significant cause of the extinctions. Increased toxicity of PSCs in the pika diet under elevated temperature may have played a role in the extirpation of these populations. Pikas are known for their seasonal variability in diet selection (Huntly et al. 1986; Dearing 1997b). The summer diet is consumed immediately and is low in PSCs. In contrast, the winter diet is stored for consumption during the winter and has initially high PSC concentrations that decay to palatable levels after months of storage (Dearing 1997a, 1997b). If PSC toxicity in pikas is temperature sensitive, then warmer temperatures in autumn and early winter may restrict the ability of a pika to consume the toxic plants stored in the winter diet, which could negatively affect winter survival and potentially lead to local extinctions.

If we assume that a general effect of elevated temperature on herbivorous mammals is to lower the toxic dose of PSCs, we propose the following hypotheses for future study. We predict that the mammalian herbivores most influenced by global warming will be generalist species that ingest PSCs, folivores in particular. Folivorous mammals tend to ingest more PSC than granivorous ones because grasses invest less in chemical defense than trees and shrubs (Crawley 1997). Generalists appear to be more sensitive to concentration changes and less able to cope with increases in PSC concentrations from a single plant species in their diet than specialists (Sorensen et al. 2005a). Specialist herbivores are predicted to have evolved efficient biochemical mechanisms to deal with the PSCs in their diet (Green et al. 2004; Sorensen et al. 2005a, 2005b; Haley et al. 2007) and therefore are likely have a physiological tolerance in excess of the average concentration ingested daily. Thus, specialists are predicted to be able to cope with increases in toxicity of their host plant. In addition, it could be fruitful to examine herbivorous mammals with documented seasonal differences in diets because these may be species with temperatureinduced differences in toxicity. Finally, because warming is expected to be greater in arid regions than in mesic habitats (Solomon et al. 2007), desert herbivores may be more affected than forest or savannah dwellers.

\section{PSCs and Thermoregulation}

One physiological mechanism linking thermoregulation to PSCs is regulated hypothermia, whereby small mammals enhance their ability to detoxify a xenobiotic compound by downregulating their $T_{\mathrm{b}}$ (Gordon 1993). As ambient temperature increases, the ability of a mammal to dissipate heat and downregulate temperature may also decrease such that it would be more difficult to detoxify compounds via regulated hypothermia at higher ambient temperatures (Gordon et al. 1988; Gordon 1993). For example, the lethal doses of 57 diverse xenobiotics (e.g., caffeine, ephedrine) were significantly lower when laboratory rats were tested at higher ambient temperatures (i.e., the lower the lethal dose, the more toxic the compound; Keplinger et al. 1959). Interestingly, the higher temperatures used in these previous experiments were within the animal's TNZ, while the lower temperatures were slightly below the lower critical temperature. We see a parallel with this study in that $N$. albigula was less tolerant of juniper PSCs at ambient temperatures within its TNZ than at temperatures below its TNZ. However, we did not observe the expected decrease in $T_{\mathrm{b}}$ associated with regulated hypothermia, suggesting that regulated hypothermia may not play a role in N. albigula. Nevertheless, any interference with thermoregulation that causes an increase in $T_{\mathrm{b}}$ at warmer ambient temperatures would tend to increase the toxicity of the PSCs in juniper. Given that the only observed increase in $T_{\mathrm{b}}$ in this study was in woodrats exposed to juniper 
(Table 1), it seems plausible that juniper contains PSCs that interfere with thermoregulation.

One or more of the specific PSCs in juniper could have a direct pharmacological effect on thermoregulation in N. albigula. Vasoconstriction induced by PSCs or other toxins can hinder the ability to dissipate heat under warm conditions, sometimes dangerously so (e.g., fescue toxicosis; Oliver et al. 1993), and other species of juniper contain PSCs that are vasoactive (Gardner et al. 1998). McLister et al. (2004) found that the thermoregulatory effect of juniper on $N$. albigula was most likely attributable to reduced heat dissipation (i.e., lower conductance), and the elevated $T_{\mathrm{b}}$ observed for $N$. albigula that ate juniper in this study is also consistent with reduced heat dissipation.

Alternatively, juniper could contain PSCs that induce thermogenesis. Although thermogenesis has not yet been demonstrated for any known PSCs in juniper, other PSCs, such as capsaicin and caffeine, are noted for their thermogenic activity in humans (Westerterp-Plantenga et al. 2006). Turpentine contains PSCs similar to those in juniper (Mirov et al. 1962; Adams et al. 1981) and is routinely used to experimentally induce hyperthermia in laboratory animals (Xie et al. 2006; Hernández-Espinosa et al. 2007). Subcutaneous administration of turpentine elevated $T_{\mathrm{b}}$ of mice (Hernández-Espinosa et al. 2007) and rabbits (Xie et al. 2006) more than $1^{\circ} \mathrm{C}$ for $6-24 \mathrm{~h}$ after administration. Furthermore, if PSCs in juniper are thermogenic or vasoconstrictive, woodrats would experience increased toxicity at ambient temperatures within or above their TNZ because of a reduced ability to transfer heat. In contrast, at temperatures below the TNZ-that is, $20^{\circ} \mathrm{C}$-woodrats can more easily dissipate excess body heat to the environment. The $T_{\mathrm{b}}$ and RMR were significantly greater in woodrats that consumed juniper than in those on the control diet (Table 1). Also, the $1.6^{\circ} \mathrm{C}$ elevation in $T_{\mathrm{b}}$ of woodrats consuming juniper at $28^{\circ} \mathrm{C}$, compared with those eating a nontoxic diet, is considered toxic or pyretic in other species (Xie et al. 2006).

Regardless of whether juniper PSCs are vasoactive or thermogenic, woodrats under winter conditions could benefit from the thermal consequences of ingesting juniper (McLister et al. 2004). Increased ingestion of juniper by N. albigula in the winter has been attributed to a reduction in availability of more preferred items (Dial 1988). The possibility exists that woodrats increase juniper consumption in winter because it is less toxic under the colder ambient conditions and ingestion has marked thermoregulatory benefits (McLister et al. 2004). Therefore, $N$. albigula could be deliberately increasing its juniper consumption in the winter to enhance thermoregulation. Other mammalian herbivores that do not hibernate may also capitalize on reduced toxicity and enhanced thermoregulatory properties of PSCs at cooler ambient temperatures.

Our results indicate that woodrats under laboratory conditions respond to changes in ambient temperatures by significantly altering diet selection to reduce incorporation of toxic plants. In the future, we will expand our research to test other species of woodrats as well as other species of small mammals.
It would be of great interest to know how broadly this phenomenon applies to other mammalian herbivores, particularly those with larger body sizes. We are not equipped to conduct studies on large mammals in our laboratory but hope that others with facilities for animals $>10 \mathrm{~kg}$ will undertake such studies in the near future. In addition to laboratory studies, it is essential to expand this work to population-level studies to determine how the changes observed in individuals will play out in populations under field conditions. Such results could yield critical information for predicting the distributions of herbivorous mammals relative to changing temperatures in the next century.

\section{Acknowledgments}

We thank W. Hudson from Wupatki National Monument for providing housing during woodrat collecting trips. H. Baldwin, R. Boyle, D. Greene, C. Heilderberger, and S. O'Grady assisted in collecting woodrats in the field; C. Turnbull, E. Van Dijk, J. Thammavong, and J. Morris contributed to the care and maintenance of the woodrat colony at the University of Utah; J. Thammavong and J. Morris assisted in data collection. K. Smith assisted with manuscript preparation. Two anonymous reviewers provided insightful comments. This work was supported by National Science Foundation grant IBN 0236402 to M.D.D.

\section{Literature Cited}

Adams R.P., T.A. Zanoni, E. von Rudloff, and L. Hogge. 1981. The southwestern USA and northern Mexico one-seeded junipers: their volatile oils and evolution. Biochem Syst Ecol 9:93-96.

Aubert A., G. Goodall, and R. Dantzer. 1995. Compared effects of cold ambient temperature and cytokines on macronutrient intake in rats. Physiol Behav 57:869-873.

Bale J.S., G.J. Masters, I.D. Hodkinson, C. Awmack, T.M. Bezemer, V.K. Brown, J. Butterfield, et al. 2002. Herbivory in global climate change research: direct effects of rising temperature on insect herbivores. Global Change Biol 8:1-16.

Beever E.A., P.F. Brussard, and J. Berger. 2003. Patterns of apparent extirpation among isolated populations of pikas (Ochotona princeps) in the Great Basin. J Mammal 84:3754.

Bozinovic F. and F.F. Novoa. 1997. Metabolic costs of rodents feeding on plant chemical defenses: a comparison between an herbivore and an omnivore. Comp Biochem Physiol A 117:511-514.

Crawley M. 1997. Plant-herbivore dynamics. Pp. 401-474 in M. Crawley, ed. Plant Ecology. Blackwell Science, Oxford.

Dearing M.D. 1997a. Effects of Acomastylis rossii tannins on a mammalian herbivore, the North American pika, Ochotona princeps. Oecologia 109:122-131.

- 1997b. The manipulation of plant toxins by a foodhoarding herbivore, Ochotona princeps. Ecology 78:774-781. 
Dearing M.D., A.M. Mangione, and W.H. Karasov. 2000. Diet breadth of mammalian herbivores: nutrient versus detoxification constraints. Oecologia 123:397-405.

Depocas F. and J.S. Hart. 1957. Use of the Pauling oxygen analyzer for measurement of oxygen consumption of animals in open-circuit systems and in a short-lag, closed-circuit apparatus. J Appl Physiol 10:388-392.

Dial K.P. 1988. Three sympatric species of neotoma dietary specialization and coexistence. Oecologia 76:531-537.

Gardner D.R., K.E. Panter, L.F. James, and B.L. Stegelmeier. 1998. Abortifacient effects of lodgepole pine (Pinus contorta) and common juniper (Juniperus communis) on cattle. Vet Hum Toxicol 40:260-263.

Gordon C.J. 1993. Temperature Regulation in Laboratory Rodents. Cambridge University Press, New York.

Gordon C.J., F.S. Mohler, W.P. Watkinson, and A.H. Rezvani. 1988. Temperature regulation in laboratory mammals following acute toxic insult. Toxicology 53:161-178.

Grayson D.K. 2005. A brief history of Great Basin pikas. J Biogeogr 32:2103-2111.

Green A.K., S.L. Haley, M.D. Dearing, D.M. Barnes, and W.H. Karasov. 2004. Intestinal capacity of P-glycoprotein is higher in the juniper specialist, Neotoma stephensi, than the sympatric generalist, Neotoma albigula. Comp Biochem Physiol A 139:325-333.

Haley S.L., J.G. Lamb, M.R. Franklin, J.E. Constance, and M.D. Dearing. 2007. Xenobiotic metabolism of plant secondary compounds in juniper (Juniperus monosperma) by specialist and generalist woodrat herbivores (genus Neotoma). Comp Biochem Physiol C 146:552-560.

Hernández-Espinosa D., R. Mota, A. Miñano, A. Ordóñez, J. Yélamos, V. Vicente, and J. Corral. 2007. In vivo effects of hyperthermia on the functional and conformational characteristics of antithrombin. J Thromb Haemost 5:963-970.

Hiebert S.M., E.K. Fulkerson, K.T. Lindermayer, and S.D. McClure. 2000. Effect of temperature on preference for dietary unsaturated fatty acids in the Djungarian hamster (Phodopus sungorus). Can J Zool 78:1361-1368

Huntly N.J., A.T. Smith, and B.L. Ivins. 1986. Foraging behavior of the pika Ochotona princeps with comparisons of grazing vs. haying. J Mammal 67:139-148.

Keplinger M.L., G.E. Lanier, and W.B. Deichmann. 1959. Effects of environmental temperature on the acute toxicity of a number of compounds in rats. Toxicology 1:156-161.

Lindroth R.L., K.A. Klein, J.D.C. Hemming, and A.M. Feuker. 1997. Variation in temperature and dietary nitrogen affect performance of the gypsy moth (Lymantria dispar L.). Physiol Entomol 22:55-64.

Macedo R.H. and M.A. Mares. 1988. Neotoma albigula. Mamm Species 310:1-7.
McLister J.D., J.S. Sorensen, and M.D. Dearing. 2004. Effects of consumption of juniper (Juniperus monosperma) on cost of thermoregulation in the woodrats Neotoma albigula and Neotoma stephensi at different acclimation temperatures. Physiol Biochem Zool 77:305-312.

Mirov N.T., E. Zavarin, and J.G. Bicho. 1962. Composition of gum turpentines of pines. Pinus nelsonii and pinus occidentalis. J Pharm Sci 51:1131-1135.

Núñez-Hernández G., J.L. Holechek, J.D. Wallace, M.L. Galyean, A. Tembo, R. Valdez, and M. Cardenas. 1989. Influence of native shrubs on nutritional status of goats: nitrogen retention. J Range Manag 42:228-232.

Oliver J.W., L.K. Abney, J.R. Strickland, and R.D. Linnabary. 1993. Vasoconstriction in bovine vasculature induced by the tall fescue alkaloid lysergamide. J Anim Sci 71:2708-2713.

Schmidt-Nielsen K. 1993. Animal Physiology: Adaptation and Environment. Cambridge University Press, New York.

Smith F.A. and J.L. Betancourt. 2006. Predicting woodrat ( $\mathrm{Ne}$ otoma) responses to anthropogenic warming from studies of the palaeomidden record. J Biogeogr 33:2061-2076.

Smith F.A., J.L. Betancourt, and J.H. Brown. 1995. Evolution of body size in the woodrat over the past 25,000 years of climate change. Science 270:2012-2014.

Smith F.A., H. Browning, and U.L. Shepherd. 1998. The influence of climate change on the body mass of woodrats $\mathrm{Ne}$ otoma in an arid region of New Mexico, USA. Ecography 21:140-148.

Solomon S., D. Qin, M. Manning, R.B. Alley, T. Bertsten, N.L. Bindoff, Z. Chen, et al. 2007. Technical Summary: Climate Change 2007: The Physical Science Basis. Contribution of Working Group I to the Fourth Assessment Report of the Intergovernmental Panel on Climate Change. Cambridge University Press, Cambridge.

Sorensen J.S., E. Heward, and M.D. Dearing. 2005a. Plant secondary metabolites alter the feeding patterns of a mammalian herbivore (Neotoma lepida). Oecologia 146:415-422.

Sorensen J.S., J.D. McLister, and M.D. Dearing. 2005b. Plant secondary metabolites compromise the energy budgets of specialist and generalist mammalian herbivores. Ecology 86: 125-139.

Vaughn T.A., J.M. Ryan, and N.J. Czaplewski. 2000. Mammalogy. 4th ed. Brooks/Cole, Independence, KY.

Westerterp-Plantenga M., K. Diepvens, A.M. Joosen, S. BerubeParent, and A. Tremblay. 2006. Metabolic effects of spices, teas, and caffeine. Physiol Behav 89:85-91.

Xie Y., W. Lu, S. Cao, X. Jiang, M. Yin, and W. Tang. 2006. Preparation of bupleurum nasal spray and evaluation on its safety and efficacy. Chem Pharm Bull 54:48-53. 